\title{
ANÁLISE DA VARIAÇÃO TERMO-HIGROMÉTRICA DOS ESPAÇOS LIVRES NA ÁREA URBANA DE LAGOA FORMOSA (MG)
}

\author{
Francielle de Siqueira Castro $^{(a)}$, Paulo Cezar Mendes ${ }^{(b)}$ e Rildo Aparecido Costa ${ }^{(c)}$ \\ (a) Programa de Pós-graduação em Geografia/Instituto de Geografia, Universidade Federal de Uberlânida, \\ franciellesiqueiracastro@gmail.com \\ (b) Programa de Pós-graduação em Geografia/Instituto de Geografia, Universidade Federal de Uberlânida, \\ pcmendes@ig.ufu.br \\ (c) Programa de Pós-graduação em Geografia/Faculdade de Ciências Integradas do Pontal, Universidade Federal de \\ Uberlânida, rildocosta1@ yahoo.com.br
}

\section{Eixo: 3. CLIMATOLOGIA EM DIFERENTES NÍVEIS ESCALARES: MUDANÇAS E VARIABILIDADES}

\begin{abstract}
Resumo/
O reflexo da relação entre os aspectos naturais e influência humana sobre o espaço traduz-se em diversos fenômenos ambientais urbanos. Nesse cenário, os espaços livres e as áreas verdes ganham destaque, principalmente por sua capacidade de influência na variação na temperatura e umidade. Assim, este trabalho objetivou investigar a dinâmica termo higrométrico nos espaços livres urbano de Lagoa Formosa (MG). A investigação científica se deu em três etapas: estruturação teórica dos temas; trabalho de campo para e levantamento empírico e sistematização e analises dos dados. Os resultados apontaram temperaturas mais elevadas e índices de umidade mais baixos no ponto de amostragem E.L.P3, características atribuídas ao padrão construtivo e a falta de arborização circundante. Em contrapartida, o ponto E.L.P2 além da representatividade arbórea, a presença do espelho d'água possibilitou a regulação térmica e propiciou que o microclima mantivesse temperaturas mais amenas e índices úmidos mais elevados em relação aos demais ambientes.
\end{abstract}

Palavras chave: clima urbano, áreas verdes, temperatura e umidade.

\section{Introdução}

O contexto da distribuição populacional do Brasil apresenta um pais majoritariamente urbano, onde cerca de 84,36\% da população, segundo o IBGE 2010, residem nas cidades. Esse universo citadino está amplamente aberto ao que há de mais interdisciplinar, tornou-se cada vez mais, a morada do homem e, portanto, em um lugar onde se produz economicamente, onde centralizam serviços, negócios, pessoas, automóveis, edificações.

O reflexo dessa estreita relação entre os aspectos naturais e influência humana sobre o espaço urbanizado traduz-se em diversos fenômenos ambientais urbanos como ilha de calor, efeito estufa, poluição atmosférica, inversão térmica, impermeabilização do solo dentre outras. Essa rápida multiplicação da população humana e sua ocupação nos mais diversos espaços nas áreas urbanas, forçou a adaptação das mesmas às condições a ele delimitadas, sejam estas: climáticas, topográficas, espaciais e/ou sociais. 
E é sobre esse cenário que os espaços livres e as áreas verdes ganham destaque, visto que, suscitam a pauta dos aspectos que clamam pela preservação e implantação de espaços destinados a elementos naturais no ambiente citadino, sem relegar sua função nos aspectos ecológicos, sociais e estéticos (GUZZO, 1999).

O papel desempenhado pelos espaços livres, e com mais efetividade pelas áreas verdes, no mosaico urbano, vão além das questões estéticas e de marketing, onde são apresentadas "cidades-jardins descongestionadas e saudáveis" (NIEMEYER, s/d, p.2), nesse espaços encontramos benéficos reais da arborização na qualidade de vida da população, não cabe neste momento discutir o conceito de qualidade de vida mas, certamente, estes ambientes abrigam condições ecológicas mais próximas às condições normais da natureza "agindo simultaneamente sobre o lado físico e mental do Homem.” (LOBODA, 2003, p.29)

Lagoa Formosa é um município mineiro considerado, nos parâmetros do IBGE, de pequeno porte, e tem alcançado nos últimos anos um crescimento representativo com a ampliação de seus limites urbanos, com essas transformações os estudos sobre o município ganham novas perspectivas em diferentes áreas do conhecimento.

Dessa forma, o objetivo deste trabalho foi fazer uma análise comparativa do comportamento higrométrico em três espaços livres, cuja as características arbóreas, espaciais e funcionais são diferentes entre si, no episódio de inverno do ano de 2014. Para tanto, recorreu-se ao processo de investigação científica em três etapas: a primeira constituiu a estruturação teórica dos temas, a partir de bibliografias previamente selecionadas; o trabalho de campo para levantamento empírico das informações, coleta de dados termo higrométricos (temperatura e umidade) e características estruturais das unidades de amostragem, compôs a segunda etapa e por fim com a junção das etapas anteriores foi possível sistematizar e analisar os dados.

\section{Delimitação da área de estudo e caracterização dos materiais e métodos}

Tem-se como recorte espacial o município de Lagoa Formosa, localizado entre as coordenadas geográficas de $18^{\circ} 46^{\prime} 44^{\prime \prime} \mathrm{S}$ e $46^{\circ} 24^{\prime}$ 28" O (Figura 1). Situa-se na Mesorregião Geográfica do Triângulo Mineiro e Alto Paranaíba e é uma das 11 cidades que compõem à microrregião de Patos de Minas, ocupa uma área de aproximadamente $844 \mathrm{Km}^{2}$ e faz limite com os municípios de Carmo do Paranaíba e Patos de Minas, ligados pela rodovia estadual BR-354.

De acordo com os dados do Instituto Brasileiro de Geografia Estatística (IBGE, 2014) a população de Lagoa Formosa passou de 15.949 em 1991 para 17.161 em 2010, segundo o mesmo banco de dados a projeção para 2013 foi de 17.885 habitantes. O aumento populacional pode em primeira análise não parecer tão significativo sob a ótica quantitativa, porém, esse fator reflete diretamente na taxa de urbanização que em 1991 era representada por 55,7\% de sua população vivendo na cidade e já em 2010 este valor saltou para 


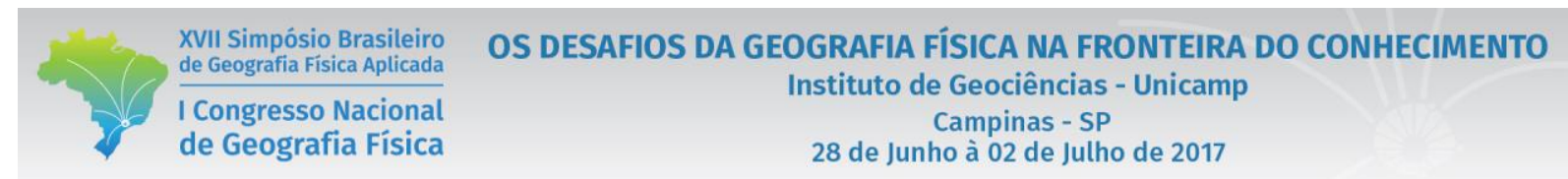

aproximadamente 75,56 \% (IBGE, 2014), o que certamente é representativo para a reestruturação urbana do município.

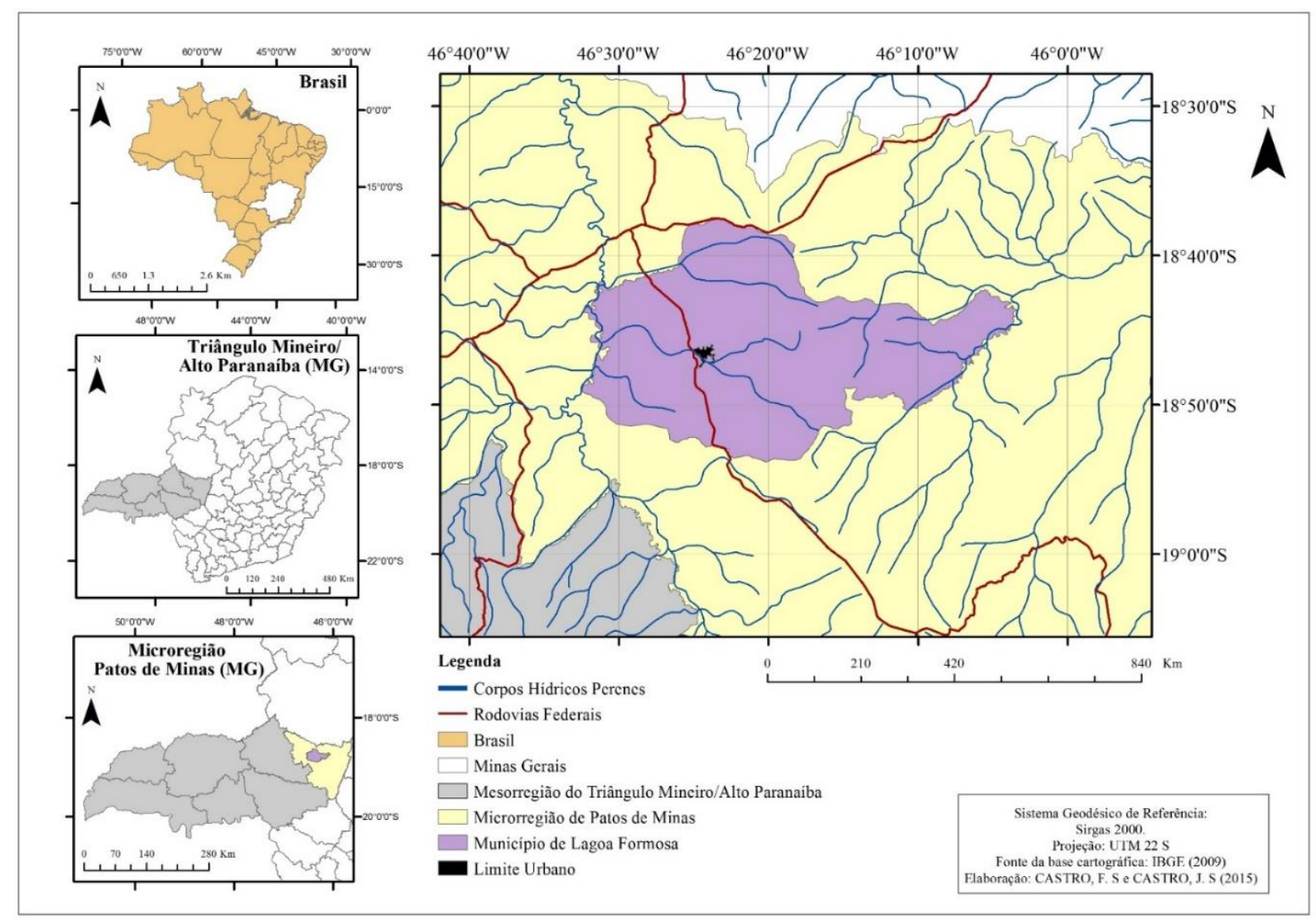

Figura 1 - Localização do município de Lagoa Formosa (MG), 2015

Fonte: Instituto Brasileiro de Geografia e Estatística (IBGE), 2009. Org.: CASTRO, F.S. 2014.

Os dados termo-higrométricos selecionados foram coletados por aparelhos climatológicos, dos quais foram utilizados datalogger; termo-higrômetro digital portátil; termo-anemômetro digital e um GPS. As medições aconteceram no período de 27 de julho à 31 de agosto de 2014, uma escala temporal de cinco dias.

Um dos elementos fundamentais para com o conhecimento do estado instantâneo da atmosfera e êxito na operação no sistema de coleta de dados climatológicos é a regularidade dos horários em que se fazem as observações. A designação dos horários para a coleta de dados da referida pesquisa, obedeceu ao horário padrão do INMET - Instituto Nacional de Meteorologia que segue a designação dada pela Coordenada de Tempo Universal (UTC), sendo os horários padrões 00:00, 06:00, 12:00, 18:00 UTC, transformado para o horário brasileiro teremos 03:00, 09:00, 15:00 e 21:00 horas. Porém como método de adaptabilidade excluiu-se para a pesquisa as medições no período das 03:00 horas.

Após a aquisição dos dados em campo os mesmos foram sistematizados e organizados intuindo uma melhor interpretação e consequentemente um resultado mais confiável possível, possibilitando a comprovação das 


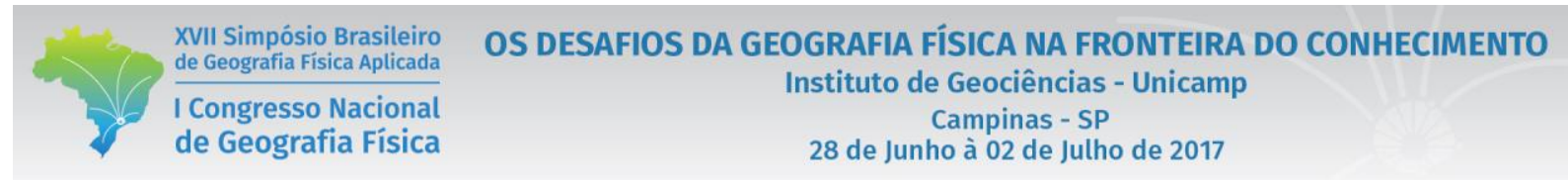

hipóteses levantadas de antemão, ou mesmo refutando-as. Os dados climáticos coletados em campo foram organizados, inicialmente, em planilhas do Microsoft Excel@ versão 2010, e posteriormente, representados através de climogramas, tabelas e gráficos também elaborados no Microsoft Excel®.

Para tanto foram selecionados, dentro da área urbana do município, três espaços livres de uso público para serem analisados, os mesmos possuem características estruturais que os diferenciam entre si, principalmente no que concerne a arborização nos locais e o tipo de uso e ocupação do solo pelo processo de urbanização circundante. Na figura 2 é possível visualizar a localização dos espaços livres na malha urbana do município supracitado, com destaque para as três unidades amostrais, selecionados por suas características geourbanas. Em seguida o quadro 1 fornece a caracterização desses ambientes.

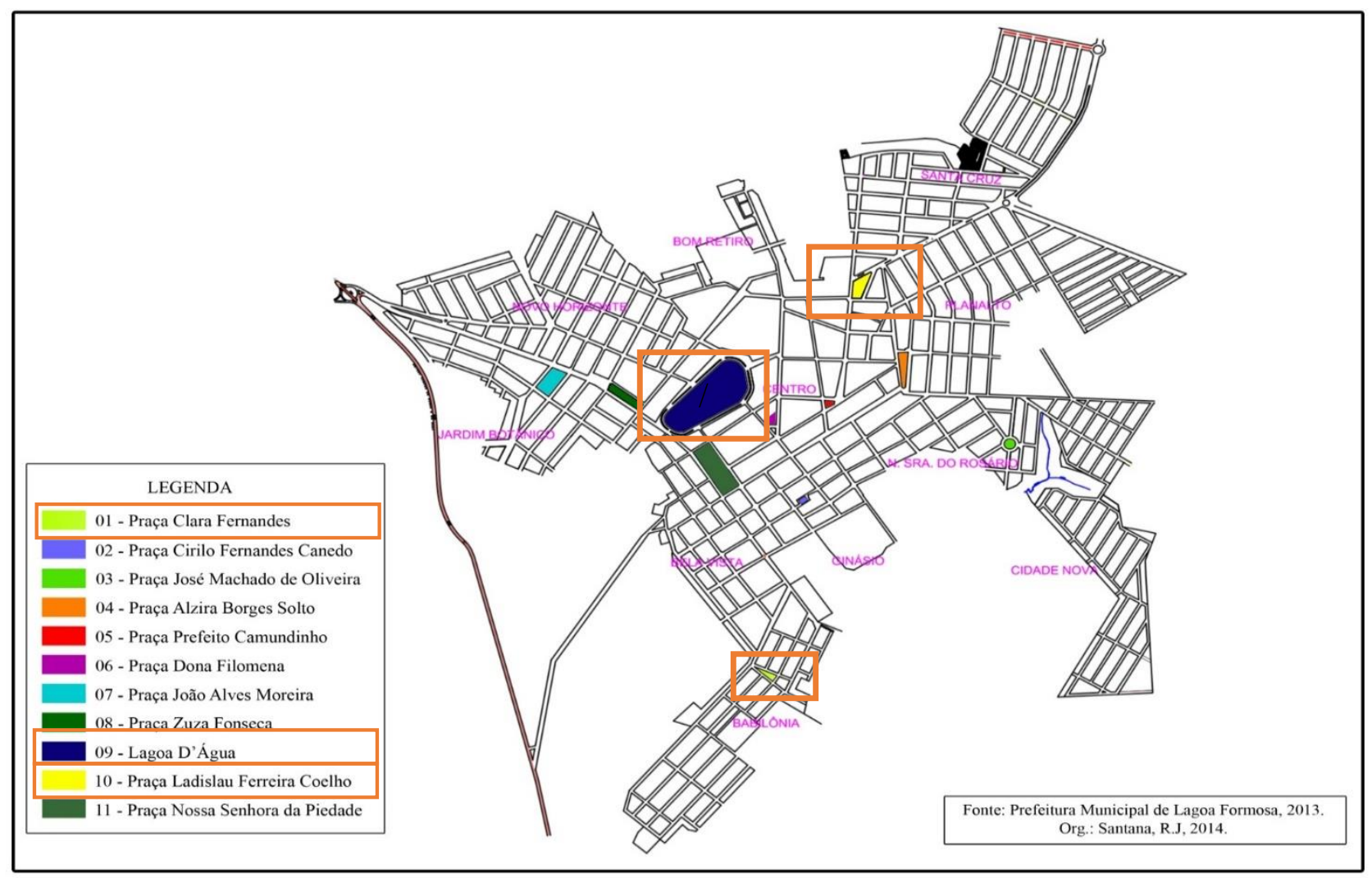

Figura 2 - Localização das praças de Lagoa Formosa.

Fonte: Prefeitura Municipal de Lagoa Formosa - MG. 2014. Org.: SANTANA, R. J. 2014.

Quadro 1 - Lagoa Formosa, localização e características das unidades de amostra

\begin{tabular}{|c|c|c|c|}
\hline $\begin{array}{l}\text { Espaços Livres } \\
\text { Públicos (E.L.P) }\end{array}$ & Logradouro & Localização & Características gerais \\
\hline E.L.P1 & $\begin{array}{l}\text { Praça Ladislau Ferreira } \\
\text { Coelho (Centro) }\end{array}$ & $\begin{array}{c}18^{\circ} 46^{\prime} 19.28^{\prime \prime} \mathrm{S} / 4 \\
6^{\circ} 24^{\prime} 6.04^{\prime \prime} \mathrm{O}\end{array}$ & $\begin{array}{l}\text { Região bem arborizada, três diferentes } \\
\text { espécies arbóreas podem ser encontradas, } \\
\text { cinamomo (Melia azedarach), balsamo } \\
\text { (Schinus molle) e coqueiro jerivá (Syagrus } \\
\text { romanzoffiana). Possui alta permeabilidade, }\end{array}$ \\
\hline
\end{tabular}




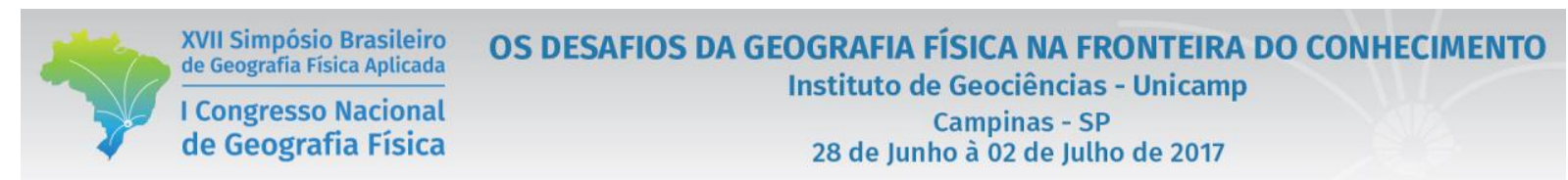

\begin{tabular}{|c|c|c|c|}
\hline & & & $\begin{array}{l}\text { função urbana voltada ao lazer e ambiente } \\
\text { residencial, também conta com fluxo médio } \\
\text { de pessoas e veículos. (Figura } 3 \text { ) }\end{array}$ \\
\hline E.L.P2 & $\begin{array}{l}\text { Av. Juscelino } \\
\text { Kubitscheck/Orla da } \\
\text { Lagoa (Centro) }\end{array}$ & $\begin{array}{c}18^{\circ} 46^{\prime} 32.20^{\prime \prime} \mathrm{S} / 4 \\
6^{\circ} 24^{\prime} 28.79^{\prime \prime} \mathrm{O}\end{array}$ & $\begin{array}{l}\text { Representa um dos cartões postais da cidade, } \\
\text { se caracteriza por compor um regulador } \\
\text { térmico no centro da cidade, além de contar } \\
\text { com espécies arbóreas (balsamo - Schinus } \\
\text { molle -, palmeira imperial - Roystonea Regia } \\
\text { - e coqueiro jerivá - Syagrus romanzoffiana - } \\
\text { ) distribuídas por toda sua extensão. O local é } \\
\text { marcado pela utilização para fins residenciais } \\
\text { e de lazer com movimentação alta de pessoas } \\
\text { e veículos. (Figura 4) }\end{array}$ \\
\hline E.L.P3 & Praça Clara Fernandes & $\begin{array}{c}18^{\circ} 47^{\prime} 10.50^{\prime \prime} / \\
46^{\circ} 24^{\prime} 21.69^{\prime \prime} \mathrm{O}\end{array}$ & $\begin{array}{l}\text { Localiza-se na periferia da cidade, } \\
\text { apresentando um contingente arbóreo } \\
\text { limitado, cerca de } 10 \text { exemplares, } \\
\text { intercalados entre palmeira de rabo-de-peixe } \\
\text { (Caryota urens) e balsamo (Schinus molle). A } \\
\text { ocupação do espaço circundante se dá por } \\
\text { conjuntos habitacionais populares. A função } \\
\text { social do ambiente vincula-se ao uso do } \\
\text { consumo e tráfico de intorpecentes, } \\
\text { relegando o sua real função. (Figura 5) }\end{array}$ \\
\hline
\end{tabular}

Fonte: Trabalho de Campo. CASTRO, F. S. 2014

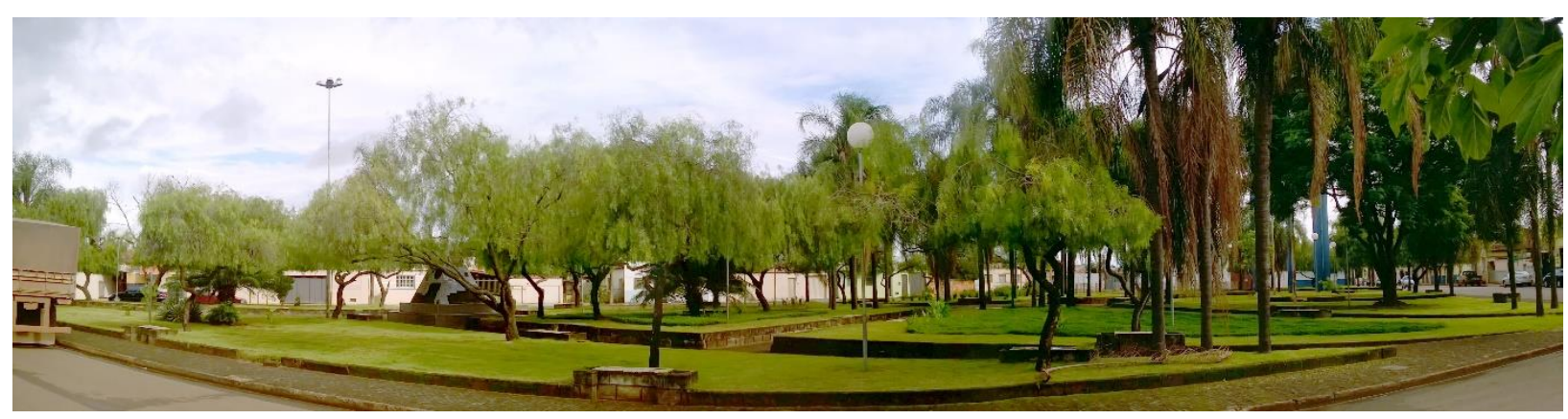

Figura 3 - Vista panorâmica da Praça Ladislau Ferreira Coelho, 2014.

Fonte: Trabalho de Campo. CASTRO, F. S. 2014.

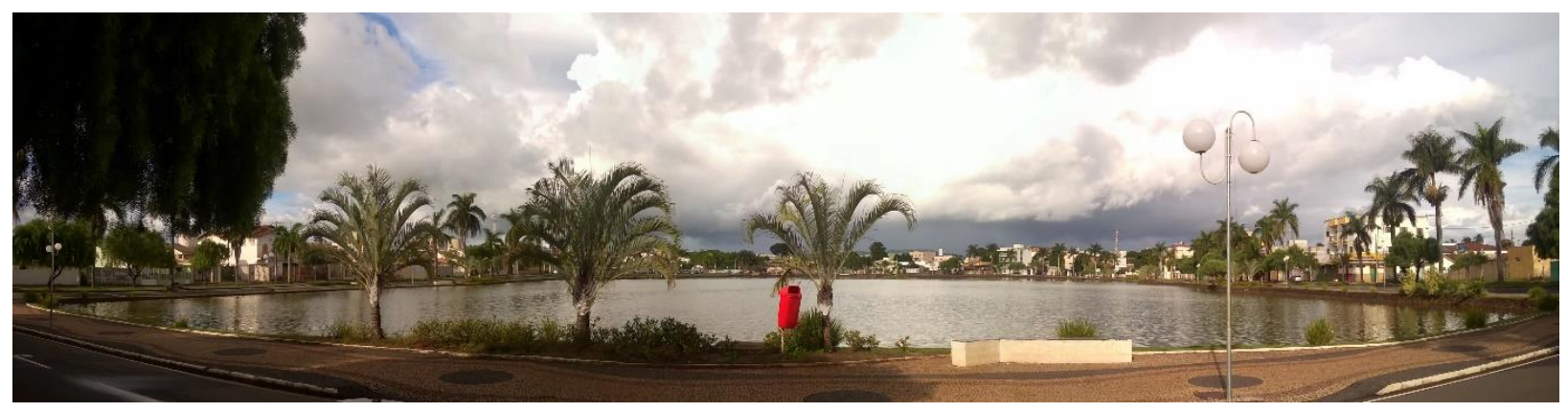

Figura 4 - Vista panorâmica da Av. Juscelino Kubitscheck/Orla da Lagoa. Fonte: Trabalho de Campo. CASTRO, F. S. 2014. 


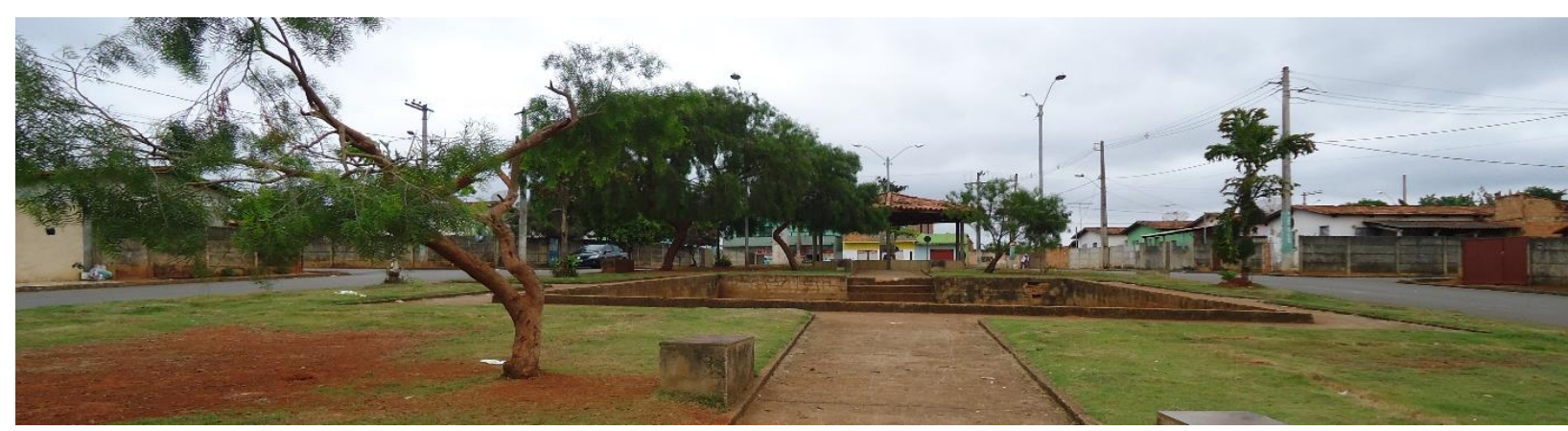

Figura 5 - Vista panorâmica da Praça Clara Fernandes, 2014.

Fonte: Trabalho de Campo. CASTRO, F. S. 2014.

\section{Os espaços livres e o clima urbano}

O desenvolvimento de uma cidade ou mesmo de sua paisagem urbana, dependerá do uso empregado pela sociedade no tempo e no espaço, desta forma torna-se produto humano, social e histórico. Esta interação dos fatores faz com que a modificação do espaço revele um fenômeno que emprega marcas consolidadas de sua vivência ao longo dos anos, como aponta Carlos (2005, p.58).

A ocupação populacional nos mais diferentes espaços, é sem dúvida uma característica da natureza humana, consequentemente a adaptação às condições delimitadas a ele, sejam essas climáticas, topográficas, espaciais e sociais, torna-se uma necessidade de sobrevivência. A designação descrita por Santos (1996, p. 37) é pertinente, pois trata o espaço habitado "segundo um ponto de vista biológico, pelo reconhecimento da adaptabilidade do homem como indivíduo, às mais diversas altitudes e latitudes, aos climas mais diversos, às condições naturais mais extremas". Sobre essa perspectiva García destaca que (1996, p.253) "La ciudad constituye la forma más radical de transformación del paisaje natural, pues su impacto no se limita a cambiar la morfología del terreno, sino que además modifica las condiciones climáticas y ambientales.".

O clima, inclui-se nessa teia de relações que afeta o rearranjo do ambiente urbano e o estudo deste fenômeno urbano têm auxiliado no equacionamento da questão ambiental das cidades. Desta maneira entende-se que a produção do clima urbano é derivada da reorganização da paisagem natural, em que há a substituição por um ambiente construído, palco de intensas atividades humanas.

A cidade gera um clima próprio (clima urbano) resultante da interferência de todos os fatores que se processam sobre a camada de limite urbano e que agem no sentido de alterar o clima em escala local. Seus efeitos mais diretos são percebidos pela população através de manifestações ligadas ao conforto térmico, à qualidade do ar, aos impactos pluviais e a outras manifestações capazes de desorganizar a vida da cidade e deteriorar a qualidade de vida de seus habitantes. (MONTEIRO E MENDONÇA, 2015, p.122)

As alterações acarretadas nas cidades se associam a fatores estruturais da dinâmica citadina (qualidade do material utilizado nas construções, arranjo do arruamento, rugosidade, asfalto, pouco ou nenhum espaço 
livre) e ao desenho urbano, que não é na maioria das vezes adaptado ao tipo de clima da região. Essas diferenciações criam microclimas dentro da cidade pelo desempenho térmico de acordo com as várias formas de uso e ocupação do solo. É o que Chandler (1962, apud VIDAL, 1991, p. 31) chama de "coleção de microclimas".

Os espaços livres representam uma possibilidade de equilíbrio entre espaços efetivamente urbanizados e os elementos naturais pré-existentes, dos quais, como aponta Mendonça 2004, o homem ainda é dependente. O conceito de espaço livre adotado trata-se do elaborado por Luiz Rodrigues Avial Llardent (1982, p. 151) onde espaços livres são: "quaisquer das distintas áreas verdes que formam o sistema de espaços livres. " Dentre as inúmeras vantagens das áreas verdes, Perci Guzzo (1999, p. 1 - 2) considera três principais: ecológica, estética e social. As "contribuições ecológicas ocorrem na medida em que os elementos naturais que compõem esses espaços minimizam tais impactos decorrentes da industrialização". "A função estética está pautada, principalmente, no papel de integração entre os espaços construídos e os destinados à circulação". "A função social está diretamente relacionada à oferta de espaços para o lazer da população". Dentre os inúmeros benefícios proporcionados pela arborização no meio urbano, o destaque deste estudo se volta para o equilíbrio solo-clima-vegetação:

[...] luminosidade e temperatura: a vegetação, ao filtrar a radiação solar, suaviza as temperaturas extremas; enriquecimento da umidade por meio da transpiração da fitomassa (300 - $450 \mathrm{ml}$ de água/metro quadrado de área); umidade e temperatura: a vegetação contribui para conservar a umidade dos solos, atenuando sua temperatura; redução na velocidade dos ventos; mantém a permeabilidade e a fertilidade do solo; embora somente parte da pluviosidade precipitada possa ser interceptada e retida pela vegetação em ambientes urbanos, esta diminui o escoamento superficial de áreas impermeabilizadas; abrigo à fauna existente; · influência no balanço hídrico. (LOBODA, 2003, p.29)

Pressupõe-se desta maneira que se pensar e investigar o conjunto de elementos que envolve o clima urbano, os espaços livres e a maneira que estes se manifestam na realidade, torna-se o caminho para elaboração futura de um planejamento e uma gestão mais adequada para a área urbana do município em destaque.

\subsection{A dinâmica termo-higrométrica nos espaços livres}

Apesar de no primeiro dia de análise, 27/07/2014 a carta sinótica não ter apresentado nenhuma anomalia, no dia 25/07/2014, foi identificada uma frente fria entre o extremo norte da Bolívia, centro de RO e de MT, sul de GO, oeste e sul de SP. (Figura 6) a este fato são atribuídas uma ligeira queda nas temperaturas coletadas e um aumento nos percentuais de umidade, nos dois primeiros dias inclusive com precipitações causadas pelo avanço do sistema frontal sobre a região. Nos dias subsequentes, após a passagem da frente fria, houve um aumento das temperaturas e consequentemente uma diminuição dos percentuais de umidade do ar, fenômeno este, causado pela diminuição rápida da nebulosidade devido a chegada do sistema polar • 
XVII Simpósio Brasileiro de Geografia Fisica Aplicada

I Congresso Nacional de Geografia Física
OS DESAFIOS DA GEOGRAFIA FÍSICA NA FRONTEIRA DO CONHECIMENTO

Instituto de Geociências - Unicamp

Campinas - SP

28 de Junho à 02 de Julho de 2017

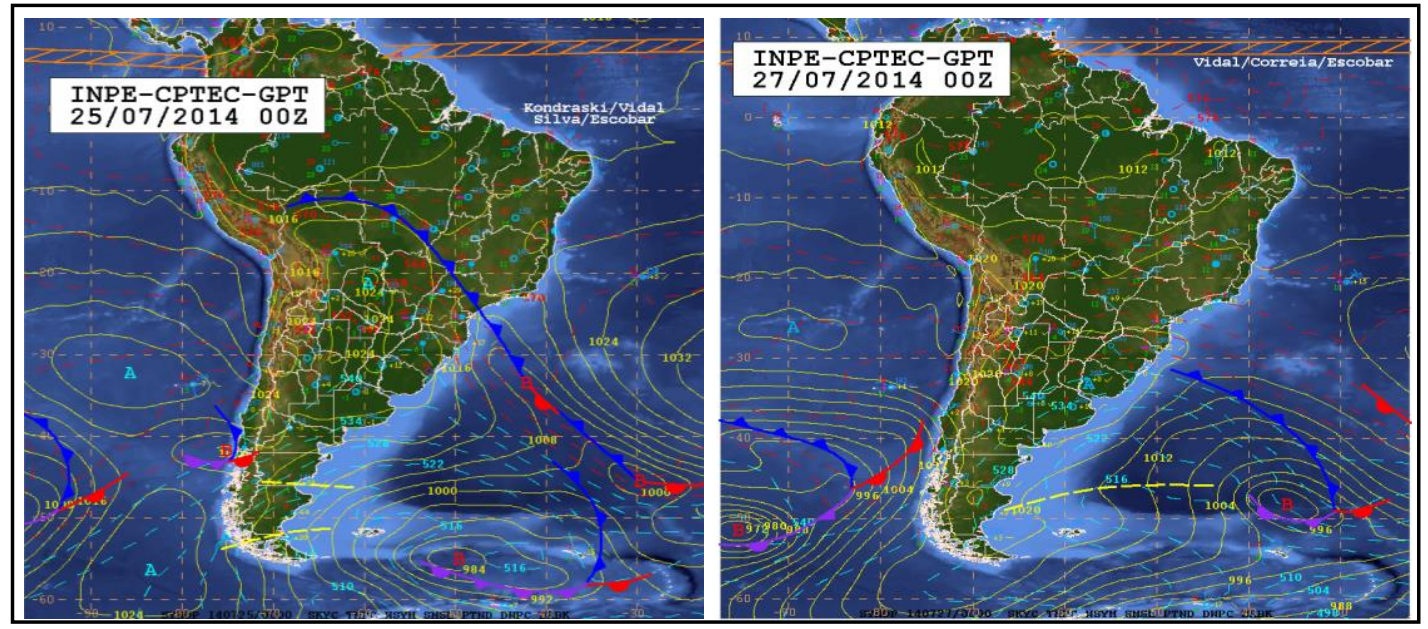

Figura 6 - América do Sul, análise sinótica da situação atmosférica no dia 25 e 27/12/2014

Fonte: Centro de Previsão de Tempo e Estudos Climáticos (CPTEC/INPE), 2014.

É possível notar no gráfico 1, que no período da manhã (09h) a diferença entre a maior e a menor temperatura oscilou entre o valor mínimo de aproximadamente $1,5^{\circ} \mathrm{C}$ no dia $27 / 07$, chegando a $3,1^{\circ} \mathrm{C}$ no dia $28 / 07$. As analises apontam para um aquecimento recorrente no E.L.P3, a média das temperaturas para o ponto supracitado foi de $21^{\circ} \mathrm{C}$, enquanto os demais foram de 19,6 (E.L.P1) e $19^{\circ} \mathrm{C}$ para o (E.L.P2). Apenas no primeiro dia de coleta a temperatura mais elevada não foi registrada no E.L.P3, porém a diferença para o E.L.P 1, foi de apenas $0,2^{\circ} \mathrm{C}$. O dia em que os registros térmicos alcançaram maior valor foi em 31/07 com média de $22,8^{\circ} \mathrm{C}$, explicado pelo distanciamento das massas de ar fria.

Os índices de umidade apresentam o E.L.P2, como aquele em que os registros são os mais significantes $86,4 \%$ ), foi também no primeiro dia que a porcentagem de umidade esteve mais elevada na casa dos $80 \%$, já os registros menos expressivos foram observados no dia 31 de julho, com menor registro 54.7\% no E.L.P 3. A média higrométrica registrada no período da manhã foi de aproximadamente $70 \%$.

No dia 27/07, às $15 \mathrm{~h}$, as temperaturas se mantiveram amenas, a menor temperatura registrada foi no E.L.P3 com $17,8^{\circ} \mathrm{C}$, a diferença para o E.L.P2 é de apenas $0,3^{\circ} \mathrm{C}$, já a maior temperatura de $19,4^{\circ} \mathrm{C}$ foi registrada no E.L.P1. A umidade foi também elevada no primeiro dia de coleta com maior percentual no E.L.P2 (88\%). Este foi um dia com anomalia como já citado anteriormente e por essa razão os dias que se seguiram apresentaram uma outra configuração. (Gráfico 2). Nos dias subsequentes a temperatura esteve acima de $20^{\circ} \mathrm{C}$ em todos os pontos, com destaque para o E.L.P3 que esteve sempre com o maior registro, chegando a $27,6^{\circ} \mathrm{C}$ no dia $31 / 07$. Já em contraponto as temperaturas mais amenas foram as registradas no E.P.L2, com média de $22,3^{\circ} \mathrm{C}$. A diferença mais elevada entre o maior (E.L.P3) e o menor (E.P.L2) registro do dia aconteceu em 29 de julho, sendo $3,1^{\circ} \mathrm{C}$. 


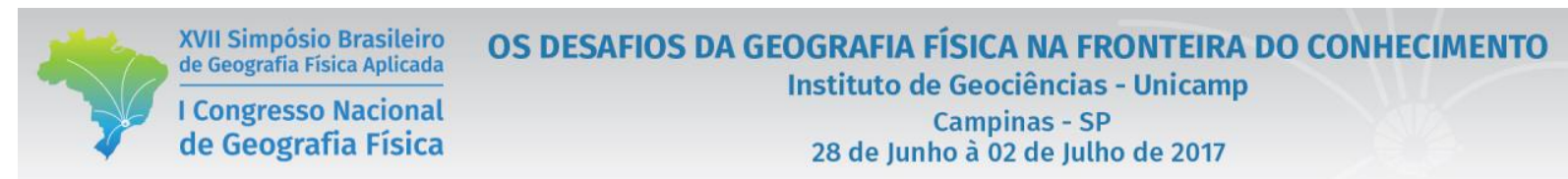

Os dados higrométricos seguiram a perspectiva das temperaturas e diminuíram ao longo dos dias de coleta chegando a $41 \%$ no E.L.P 2, no último dia de coleta. Nota-se que a umidade foi regular nos pontos de coleta mantendo uma diferença menor que $5 \%$ entre eles.

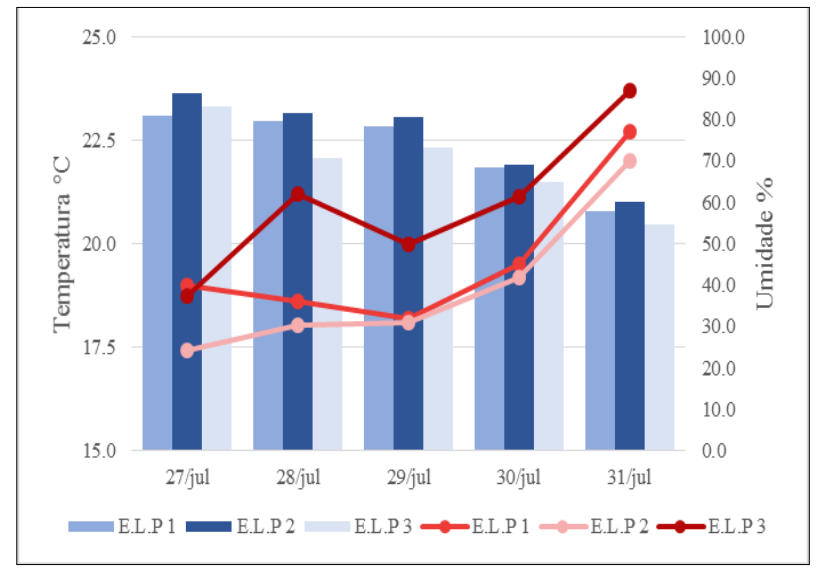

Gráfico 1 - Climograma de temperatura $\left({ }^{\circ} \mathrm{C}\right) \mathrm{e}$ umidade do ar (\%), 09:00h

Fonte: Trabalho de Campo. CASTRO, F. S. 2014.

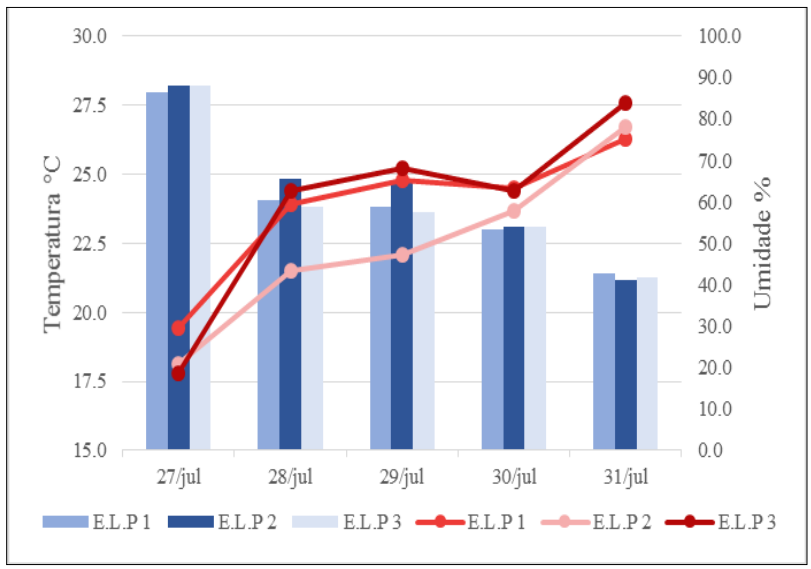

Gráfico 2 - Climograma de temperatura $\left({ }^{\circ} \mathrm{C}\right)$ e umidade do ar (\%), 15:00h

Fonte: Trabalho de Campo. CASTRO, F. S. 2014.

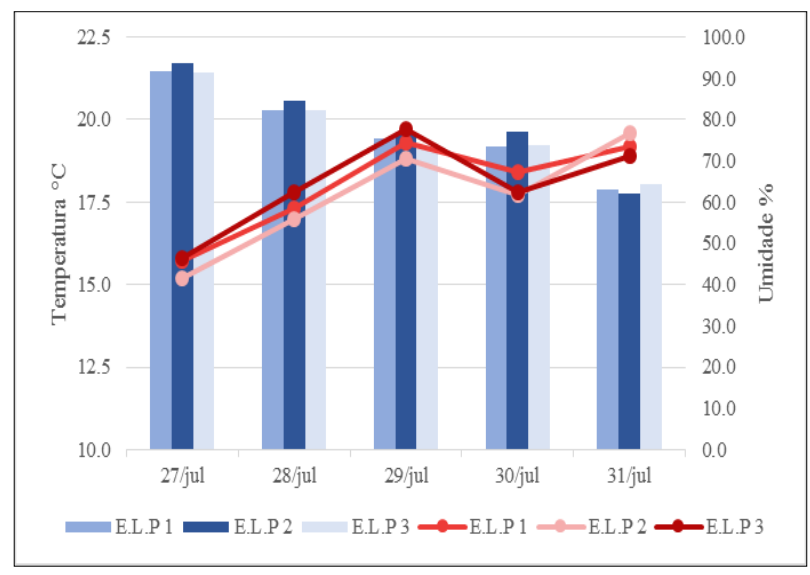

Gráfico 3 - Climograma de temperatura $\left({ }^{\circ} \mathrm{C}\right) \mathrm{e}$ umidade do ar (\%), 21:00h

Fonte: Trabalho de Campo. CASTRO, F. S. 2014.

O período noturno, cujo os dados foram registrados às 21:00 horas, apresentaram em todos os pontos de amostragem a menor temperatura e consequentemente os maiores valores para umidade do ar, ao longo dos dias. A temperatura mínima alcançada entre os dias de coleta foi de $15,2^{\circ} \mathrm{C}$ no dia $27 / 07$, no E.L.P 2 , porém as diferenças de temperatura nesta data, assim como os demais dias, não tiveram grande variação, a maior diferença foi registrada no dia $31 / 07 \mathrm{com}$ aproximadamente $0,5^{\circ} \mathrm{C}$ entre o maior e menor registro.

Os índices higrométricos mostram que o E.L.P 2 apresentou o ponto máximo de umidade (93,7\%) no primeiro dia de amostragem e o mínimo $(62,1 \%)$ no dia 31/07, porém foi nele que em média a umidade se 
mostrou mais relevante, ou seja, no período noturno foi o ponto com maior umidade. Em contraponto a isso o E.L.P3 foi observado como o menos úmido com $77,1^{\circ} \%$, uma média alta para a referida estação do ano (inverno).

Em suma os dados apontaram que espaço livre que apresentou maior temperatura ao longo dos dias de coleta de dados foi E.L.P3, representado pela Praça Clara Fernandes. Neste local o contingente arbóreo é limitado e a ocupação da terra urbana se dá por conjuntos habitacionais populares com lotes quase que totalmente impermeabilizados e sem a presença de espécies arbóreas nos mesmos. Foi observado também que no ponto E.L.P3 a densidade e a proximidade das edificações vêm atuando como uma barreira física, dificultando a circulação dos ventos sobre a área amostrada. Essa condições aparesentadas podem estar relacionadas com o registro de temperaturas mais elevadas e umidade amenas neste local, principalmente no período da manhã e tarde, onde a incidência dos raios solares sobre o ambiente é mais efetiva e a radiação solar absorvida aumenta a partir das características do material construtivo e seu poder de absorção.

O ambiente que demonstrou, no inverno de 2014, temperaturas mais amenas, proporcionando um conforto térmico maior a população, é na Avenida Juscelino Kubitscheck, local este representado pelo cartão postal da cidade a Lagoa D’água, além da representatividade arbórea a presença do espelho d'água possibilitou a regulação térmica em que o microclima mantivesse temperaturas mais amenas e índices úmidos mais elevados durante o dia, já no período noturno não ouve alternância no padrão de aquecimento e resfriamento em relação aos demais ambientes.

Já a praça Ladislau Ferreira Coelho apesar de se localizar no centro da cidade, o que tendenciaria ao aquecimeento justificado pela intesificação do fluxo de pessoas e veículos, é um ambiente com arborização considerável o que justifica a permanencia das tempearaturas mais amenas e de indices de umidade do ar mais constantes.

Nota-se, também a partir dos estudos realizados, que os espaços livres centrais são as que recebem maior atenção do Poder Público quanto sua preservação e manutenção, além disso se destacam com maior número de equipamentos, espécies arbóreas e melhor estado de conservação se comparados aos demais. Foi perceptível durante os trabalhos de campo que a preocupação com implantação de espaços livres arborizados não tem sido prioridade no Planejamento Urbano local.

\section{Considerações Finais}

Lagoa Formosa, apesar de se enquadrar nos padrões de uma pequena cidade, já apresenta, como tantos outros sítios urbanos brasileiros, problemas ambientais, decorrentes, em grande medida, pelo descompasso entre o crescimento, políticas públicas e ordenamento do espaço urbano, acarretando impactos na qualidade ambiental e de vida dos citadinos. Estes impactos devem fazer parte dos elementos de análise e planejamento dos gestores urbanos, visto que estes, "continuam a ser o tipo de organização espacial onde se concentra a 
maioria das pessoas em escala mundial e, simplesmente por este motivo, já merecem atenção especial." Amorim (2000, p.309).

É possível afirmar, que a ação antrópica e as alterações produzidas no ambiente principalmente no que concerne o padrão de uso e ocupação da terra são fatores que condicionam a temperatura e a umidade relativa do ar e contribuem para a existência de um clima específico na área urbana. E a proposta diante dos resultados adquiridos é que seja realizada a identificação e a ampliação das áreas passiveis à manutenção térmica e higrométrica, como também a ampliação das áreas verdes que são potenciais para o lazer e o conforto dos citadinos. Maior rigor no planejamento do uso do solo citadino, evitando o adensamento principalmente nas áreas em expansão urbana e também na organização dos projetos de construção civil, adaptando-os as características do ambiente tropical, atentando-se para escolha dos materiais construtivos. Uma forma de garantir a funcionalidade das áreas verdes e a qualidade ambiental urbana ampara-se em ações descritas no Plano de Arborização Urbana que por sua vez compõe Plano Diretor Municipal (documento obrigatório estabelecido pela Lei Federal 10.257/2001 mais conhecido como Estatuto das Cidades é a regulamentação dos artigos 182 e 183 da Constituição Federal que estabelece parâmetros e diretrizes da política e gestão urbana no Brasil).

O Plano de Arborização Urbana garante o respaldo de execução no art. 22 da Lei 6.766/1979 - Lei do Parcelamento do Solo que impõe "desde a data de registro do loteamento, passam a integrar o domínio do Município as vias e praças, os espaços livres e as áreas destinadas a edifícios públicos e outros equipamentos urbanos, " sendo aí incluídas as áreas verdes. Pelo art. 23 da citada lei, os espaços livres, entre eles as áreas verdes, passam a integrar o domínio público do município, inclui-se as árvores que ladeiam as vias públicas fruto da arborização urbana, são bens públicos de uso comum do povo, nos termos do art. 66 do Código Civil, estando à disposição da coletividade, o que implica na obrigação municipal de gerir estes bens públicos de forma a manter as suas condições de utilização, pois "todos têm direito ao meio ambiente ecologicamente equilibrado, bem de uso comum do povo e essencial à sadia qualidade de vida, impondo-se ao poder público e à coletividade o dever de defendê-lo e preservá-lo para a presente e as futuras gerações" (art. 225 da Constituição Federal).

Infelizmente o município de estudo não conta com um Plano Diretor Municipal que regulamente os espaços livres e consequentemente traga melhoria na qualidade de vida da população, porém o município tem se empenhado nos últimos anos em projetos de incentivo ao plantio de espécies arbóreas em via pública, o que já é um caminho. 


\section{Bibliografia}

BOVO, M. C. Áreas Verdes urbanas, Imagem e Uso: um estudo geográfico sobre a cidade de Maringá-PR. Tese de (Doutorado em Geografia) Universidade Estadual Paulista, Faculdade de Ciências e Tecnologia. Presidente Prudente, 2009.

CARLOS, A. F. A. A cidade. São Paulo: Editora Contexto, 2005. 98 p.

FONSECA, C. M. Das Histórias de Colo ao Canto da Alma. Lagoa Formosa: Multiprint, 2002. 264 p.

GARCÍA, F. F. Manual de climatoligía aplicada: cliama, medio ambiente y planificación. Madrid: Sintesis S. A., 1996. 285 p. (Serie Mayor). Coleção: Espacios y Sociedades.

GUZZO, P. Estudos dos espaços livres de uso público e da cobertura vegetal em área urbana da cidade de Ribeirão Preto SP. 1999. 106f. Dissertação (Mestrado em Geociências) Instituto de Geociências e Ciências Exatas, Universidade Estadual Paulista, Rio Claro. 1999.

IBGE. Censos Demográficos. Rio de Janeiro, IBGE, 2014.

INSTITUTO NACIONAL DE PESQUISAS ESPACIAIS (INPE). Centro de Previsão do Tempo e estudos climáticos

(CPETC). Análise Sinótica. Disponível em:

<http://www.cptec.inpe.br/noticias/faces/noticias.jsp?idConsulta=\&idQuadros=142>. Acesso em: julho de 2014.

INSTITUTO NACIONAL DE PESQUISAS ESPACIAIS (INPE). Divisão de Satélites e sistemas ambientais (DSA). Acervo de Imagesn. Disponível em: < http://satelite.cptec.inpe.br/acervo/goes.formulario.logic>. Acesso em: julho de 2014.

LIMA, A. M. L. P. et al. Problemas de utilização na conceituação de termos como espaços livres, áreas verdes e correlatos. In: CONGRESSO BRASILEIRO DE ARBORIZAÇÃ̃O URBANA, 2, 1994. São Luiz/MA. Anais... São Luiz: Imprensa EMATER/MA, 1994. p. 539 - 553.

LLARDENT, L. R. A. Zonas verdes y espaços livres en la ciudad. Madrid: Closas Orcoyen, 1982.

LOBODA, C. R. Estudo das Áreas Verdes Urbanas de Guarapuava-PR. Dissertação (Mestrado em Geografia) Universidade Estadual de Maringá, UEM. Maringá, 2003.

LOBODA, C. R; ANGELIS, B. L. D. Áreas Públicas Urbanas: conceito, uso e funções. Ambiência. Guarapuava, PR, v.1 n.1, p. 125-139, jan./jun. 2005, ISSN 1808 - 0251. Disponível em: <http://www.unicentro.br/editora/revistas/ambiencia/v1n1/artigo\%20125-139_.pdf>. Acesso em: 06 jan. 2014. 
MENDONÇA, F. Clima e planejamento urbano em Londrina - proposição metodológica e de intervenção urbana a partir do estudo do campo termo-higrométrico. In: MENDONÇA, F; MONTEIRO, C. A. de F. (Org). Clima urbano. São Paulo: Contexto, 2003, 192 p.p. 93-120.

NUCCI, J. C. Qualidade ambiental e adensamento urbano: um estudo de ecologia e planejamento da paisagem aplicado ao distrito de Santa Cecília (MSP). 2 ${ }^{\mathrm{a}}$ ed. Curitiba: O Autor, 2008. 150 p. Disponível em: < http://www.geografia.ufpr.br/laboratorios/labs/arquivos/qldade_amb_aden_urbano.pdf>Acesso em: 06 jan. 2014.

SANCHOTENE, M. do C. Desenvolvimento e perspectivas da arborização urbana no Brasil. In: CONGRESSO BRASILEIRO DE ARBORIZAÇÃO URBANA, 2, 1994. São Luiz/MA. Anais... São Luiz: Imprensa EMATER/MA, 1994. p. 15-26.

SANTOS, M. A natureza do espaço - Técnica e tempo. Razão e emoção. São Paulo: Hucitec, 1996.

VIDAL, R. Influência da morfologia urbana nas alterações da temperatura do ar na cidade de Natal-RN. Dissertação (Mestrado em Geografia) - UnB/Brasília: 1991. 